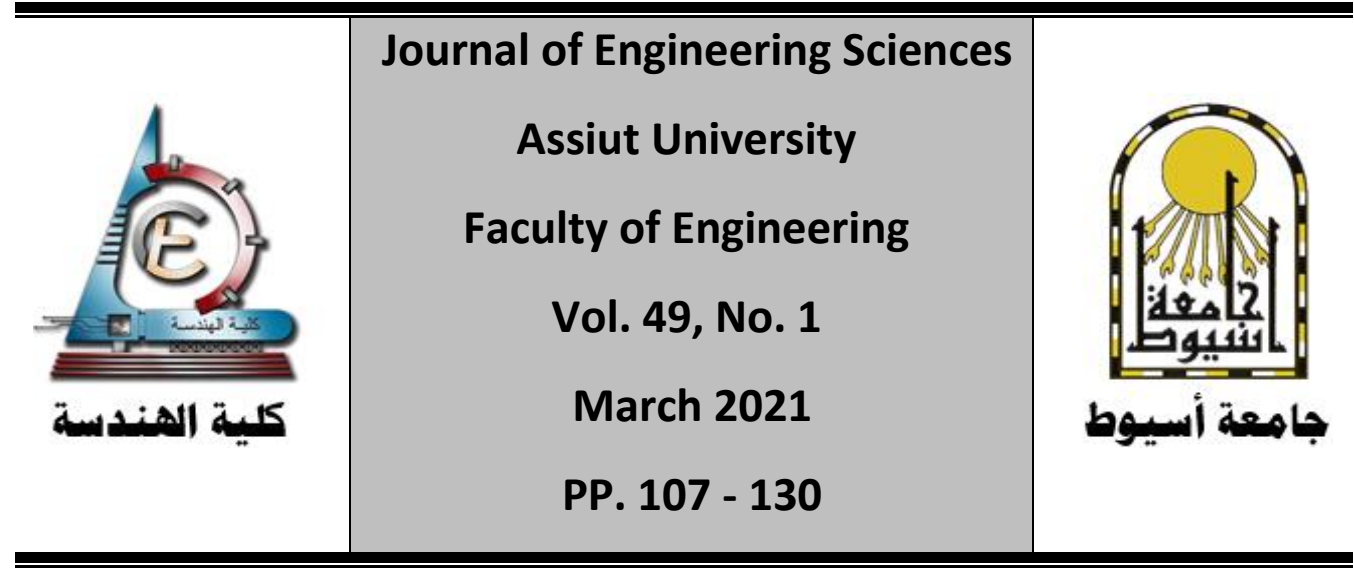

\title{
EFFECT OF CHEMICAL ADDITIVES ON THE PERFORMANCE OF ASPHALT PAVEMENT EXPOSED TO WASTEWATER
}

\author{
Hassan Y. Ahmed ${ }^{1}$, Ayman M. Othman ${ }^{2}$, Mostafa D. Hashem ${ }^{3}$ \\ and Samir Azmy Abdalla ${ }^{4}$
}

\footnotetext{
${ }^{1}$ Prof. Civil Engineering Department, Faculty of Engineering, Assiut University, EGYPT

${ }^{2}$ Prof. Civil Engineering Department, Faculty of Engineering, Aswan University, EGYPT

${ }^{3}$ Prof. Civil Engineering Department, Faculty of Engineering, Minia University, EGYPT

${ }^{3}$ Assistant Lecturer Civil Engineering Dept., Higher Institute of Engineering and Technology, El-Minia, Egypt.
}

Received 21 October 2020; Revised 28 January 2021; Accepted 02 February 2021

\begin{abstract}
It is known that water is the first enemy of asphalt pavement, and its danger increases when the water is a product of sewage because it contains organic materials and acids. The most common technique to mitigate moisture damage is using additives or modifiers with the asphalt binder. This research aims to study the effect of wastewater on the mechanical properties of HMA containing chemical additives. Three different chemical additives were used. The chemical additives were Addicrete PVS, Adibond 65, and Silica Gel that were added with different percentages $5,10,15$, and $20 \%$ by the weight of optimum asphalt content (OAC) in addition to the original mix. Asphalt 60/70 was mixed with several concentrations of each additive by using a high shear
\end{abstract}


mixer at a temperature of $130{ }^{\circ} \mathrm{C}$ and a speed of $4000 \mathrm{rpm}$ for 30 minutes. All asphalt mixtures were submerged in wastewater for 3, 7, and 15 days. Marshall and Indirect tensile strength tests were performed on these exposed mixtures. despite the wastewater decreased the mechanical properties of all mixtures, the additives decrease that effect with pronounced values. The results showed that the best content for adding these additives to the mixture was $10 \%$ for using Addicrete PVS and Silica gel while it was 5\% for using Adibond 65. The best additive was Addicrete PVS with 10\% content as it gives the highest value of Marshall stability, Marshall stiffness, Marshall quotient, and indirect tensile strength.

Keywords: Addicrete PVS, Adibond 65, Silica gel, and hot mix asphalt

\section{Introduction}

Moisture is one of the foremost sources of deterioration in flexible pavements. Moisture damage described as the degradation of the mechanical properties of specimens brought on by using moisture [1]. Bhasin et al. mentioned that most of the early checks for quantifying moisture damage focused on evaluating mechanical residences earlier than and after a conditioning process [2]. Putman and Amirkhanian compared the performance of Stone Matrix Asphalt (SMA) mixtures containing waste tire and carpet fibers with mixes made with commonly used cellulose and polyester fibers. The results revealed that the tire, carpet, and polyester fibers significantly improved the toughness of the mixtures, but no significant difference in permanent deformation or moisture susceptibility was found [3]. Ghada S. Moussa et al studied the impact of using high-density polyethylene [HDPE] on the moisture susceptibility of asphalt mixtures. The results were concluded that implementing HDPE as a binder-additive improved the binderaggregates bonding and consequently higher moisture resistance was gained [4]. Moghadas Nejad et al. concluded that the adhesion between the binder and aggregates in a modified mixture with HDPE was increased despite the sample exposed to moisture [5]. M. Rasel et al. investigated the effect of adding PVC $(2.5 \%$ to $20 \%$ by weight of bitumen) at optimum bitumen content on the performance of bitumen grade 80/100. The results indicated that using PVC modified the bitumen properties consequently obtained a high strength mixes [6]. Prasad. B et 
al. assessed the performance of modified bitumen with plastic waste. The plastic waste was once introduced $(1 \%-9 \%)$ via the weight of the recycled bitumen. The outcomes confirmed that adding plastic waste improved the binding property, stability, density, and resistance to water [7]. Rahman, Md et al. employed two sorts of polymer the PVC and waste polyethylene to improve the performance of the asphalt mixture. The results concluded that adding waste polyethylene modifier up to $10 \%$ and waste PVC modifier up to $7.5 \%$ can be used for flexible pavement construction in a warmer region due to the high values of stability, stiffness, and voids characteristics [8]. Goh, S.W. et al. concluded that using Nano clay and carbon microfiber enhanced the mixture's performance against moisture damage [9]. The stress of vehicle wheels alongside the presence of water on the avenue surface motive the stripping of the asphalt mixture. Stripping occurs when the bond between the asphalt and the mixture is damaged via water. The water may additionally be dispatched on or in the aggregate due to the fact of incomplete drying or it can also come from some different supply after construction [10]. Attaelmanan concluded that the durability of asphalts is mostly influenced by their chemical composition [11]. Mahabir Panda et al. used reclaimed low-density polyethylene (LDPE) from carrying bags of goods for enhancing mixture performance against fatigue life, resilient modulus, resistance to moisture susceptibility as well as Marshall characteristics [12]. Hugo et al. pronounced three test methods to study the properties of bitumen-rubber binders and asphalt. The sliding plate rheometer tests for bitumen-rubber binder while tensile strain measurement and freeze-thaw test for bitumen-rubber asphalt [13]. The research gap is Limited research studies have been investigated on the effect of wastewater on the performance of hot mix asphalt.

The research objective is to study the effect of using different types of chemical additives such as Addicrete PVS, Adibond 65, and Silica gel on the reduction of the effect of wastewater.

The Research Methodology: To achieve the objectives of this research work, the following work tasks which are outlined in were conducted:

- Review the benefits of the different additives on pavement performance.

- Select the mixed materials and the types of additives to be used in this study.

- A conventional control mix designed using Marshall method was used with different types and amounts of each additive to find out the 
optimum percent of each modifier.

- The influence of the modified binder on the HMA properties was studied through laboratory testing.

- To study the effect of wastewater on the performance of asphalt mixtures modified with different additives the samples were submerged on wastewater for 3,7and 15 days and Marshall properties and indirect tensile strength was calculated in both dry and submerging conditions.

\section{Materials}

\subsection{Aggregate}

The crushed limestone was used as a coarse aggregate, siliceous sand as a fine aggregate, and limestone dust as mineral filler. The aggregate gradation was selected according to one of the commonly used gradations of the Egyptian code 2008 (Dense gradation 4C). The gradation of the combined aggregate along with the specification limit is presented in Figure1. The nominal maximum aggregate size was 19.5 $\mathrm{mm}$. The physical properties of the aggregate used in the study were presented in Table 1.

Table 1. Physical Properties of Aggregates

\begin{tabular}{|l|l|l|l|l|l|}
\hline \multirow{2}{*}{ Test } & \multicolumn{4}{|c|}{ Results } & Standard Test \\
\cline { 2 - 5 } & S1 & S2 & Sand & $\begin{array}{l}\text { Mineral } \\
\text { Filler }\end{array}$ & Method \\
\hline Bulk Specific Gravity & 2.619 & 2.628 & 2.630 & - & \multirow{2}{*}{ ASTM C127 [14] } \\
\hline SSD Specific Gravity & 2.668 & 2.701 & 2.730 & - & $\begin{array}{l}\text { ASTM C128 [15] } \\
\text { ASTM D854 [16] }\end{array}$ \\
\hline Apparent Specific Gravity & 2.728 & 2.756 & 2.781 & 2.632 & \\
\hline Water Absorption (\%) & 1.95 & 1.4 & 2.940 & - & ASTM C131 [17] \\
\hline Los Angeles & \multicolumn{7}{|c|}{29.2} & - & - & AS 13 \\
\hline
\end{tabular}




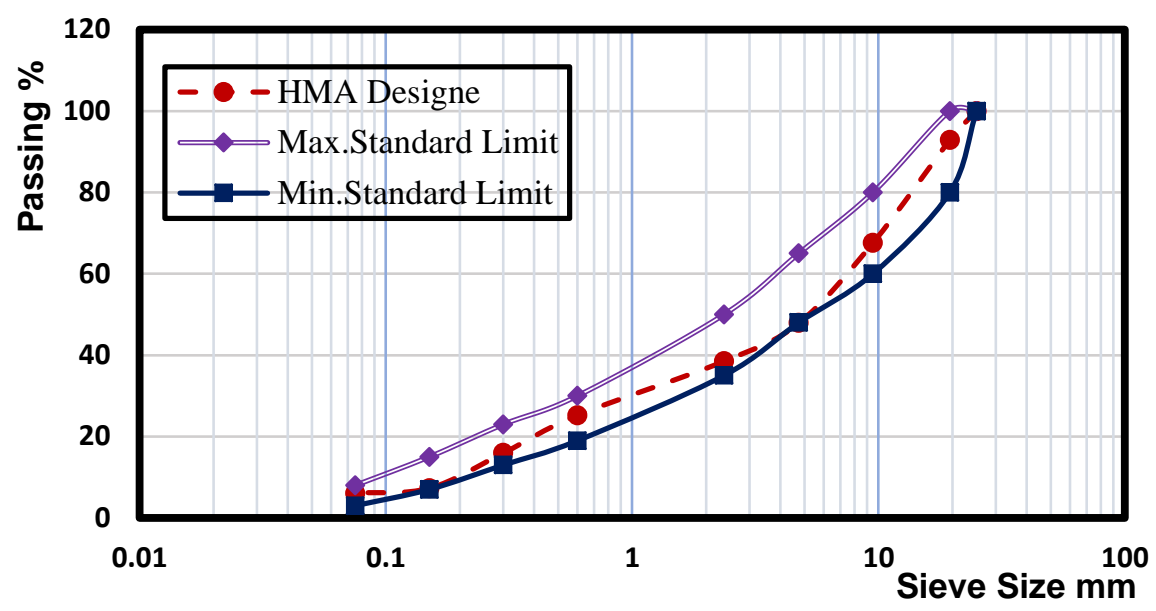

Fig.1. Mixture Aggregate Gradation

\subsection{Asphalt cement}

The asphalt cement used was AC 60/70. This asphalt material supplied by Suez Oil Processing Company is the usual asphalt grade used for asphalt pavement construction in Egypt. The physical properties of asphalt cement used are shown in Table 2.

Table 2. Physical properties of bituminous materials

\begin{tabular}{|l|l|l|}
\hline Test & Standard & AC 60/70 \\
\hline Penetration $\left(0.1 \mathrm{~mm}, 25^{\circ} \mathrm{C}, 5 \mathrm{sec}.\right)$ & ASTM D5 & 66 \\
\hline Softening Point $\left(\right.$ ring and ball), ${ }^{\circ} \mathrm{C}$ & ASTM D36 & 52 \\
\hline Flashpoint $\left({ }^{\circ} \mathrm{C}\right)$ & ASTM D92 & 250 \\
\hline Specific gravity at $25^{\circ} \mathrm{C}$ & ASTM-D70 & 1.02 \\
\hline Penetration index $(\mathrm{PI})$ & & 0.438 \\
\hline
\end{tabular}

\subsection{Additives}

Three types of chemical additives were used in this work were Addicrete PVS, Adibond 65, Silica gel. These materials have wide use in the field of concrete, as:

- Addicrete PVS is used to produce concrete with high final and early resistance.

- Adibond 65 is a superplasticizer matter used to increase the bond between the mix component.

- Silica gel is a material that absorbs moisture.

In this research, we study the validity of using these materials as modifiers used in the field of asphalt pavement by studying the effect of these materials on the performance of asphalt mixtures. The properties 
112

JES, Assiut University, Faculty of Engineering, Vol. 49, No. 1, 2021, pp. 107-130

of the additives were shown in Table 3 and Table 4 . The contents of additives in asphalt mixtures were $5 \%, 10 \%, 15 \%$, and $20 \%$ by the weight of optimum asphalt content (OAC). The additives were mixed with an asphalt binder via a wet mixing process using a high shear mixer at a temperature of $130^{\circ} \mathrm{C}$ and a speed of $4000 \mathrm{rpm}$ for 30 minutes.

Table 3. The properties of Addicrete PVS [18].

\begin{tabular}{|l|c|c|}
\hline Property & Addicrete PVS & Adibond 65 \\
\hline Density at $(\mathrm{kg} / \mathrm{L})$ & $1.21 \pm 0.01$ at $29^{\circ} \mathrm{c}$ & 1.01 at $27^{\circ} \mathrm{c}$ \\
\hline Type & Superplasticizer & $\begin{array}{c}\text { Emulsion (Latex Betadine } \\
\text { Styrene) }\end{array}$ \\
\hline Solubility in water & Soluble & Soluble \\
\hline Physical State & Brown liquid & clear white liquid \\
\hline PH & - & 10.5 \\
\hline The ratio of Solid Material & - & 44.55 \\
\hline
\end{tabular}

Table 4. The properties of Silica Gel [19].

\begin{tabular}{|l|l|}
\hline Molar weight at $25^{\circ} \mathrm{c}$ & $60.08 \mathrm{~g} /$ mole \\
\hline Chemical formula & $\mathrm{SiO} 2$ \\
\hline Solubility in water & Insoluble \\
\hline Physical state & Transparent beads \\
\hline
\end{tabular}

\subsection{Wastewater}

The wastewater used in this research is sewer water taken from the collection station of Assuit University. Table 5 presents the concentration of the sample component with $\mathrm{mg}$ for the liter of wastewater sample.

Table 5. Analysis of wastewater sample

\begin{tabular}{|l|c|}
\hline Test & Measurement Result \\
\hline Ammonia mg/l & 0.1 \\
\hline Nitrates mg/l & - \\
\hline PH & 7.92 \\
\hline Temperature $^{\circ} \mathrm{c}$ & 20 \\
\hline Dissolved Oxygen $\mathrm{mg} / \mathrm{l}^{\text {COD mg/l }}$ & 4 \\
\hline BOD mg/l & 5 \\
\hline Sulfate $\mathrm{mg} / \mathrm{l}$ & - \\
\hline Manganese $\mathrm{mg} / \mathrm{l}$ & 20 \\
\hline
\end{tabular}




\section{Experimental Work}

The coarse aggregate, fine aggregate, mineral filler, and asphalt cement were used to prepare the Marshall test specimens with $65 \mathrm{~mm}$ height and $101.6 \mathrm{~mm}$ diameter. The graduate was chosen for the tested asphalt concrete mixes as shown in Fig.1. According to the design of the mixture, the optimum asphalt content was $4.8 \%$ by weight. After Preparing the specimen it submerged into the wastewater for a different day as 3,7 and 15 days.

\subsection{Marshall test}

Additives were added separately with different concentrations to asphalt cement and 39 Marshall specimens were prepared. After mixing hot aggregate with asphalt cement with chemical modifiers, samples were compacted using a Marshall hammer with 75 blows /side to represent heavy traffic volume. Marshall test was conducted on both control and chemicals modifier mixes to evaluate their performance. Mixing and compaction temperatures for base asphalt binder were estimated using rotational viscosity at $135^{\circ} \mathrm{C}$ and $165^{\circ} \mathrm{C}$. The ranges of mixing and compaction temperatures for binder were (154.1-158.16) ${ }^{\circ} \mathrm{C}$ and (141.83-147.95) ${ }^{\circ} \mathrm{C}$, respectively.

\subsection{Indirect tensile test}

The mold of the indirect tensile test was the same as Marshall mold, also 39 specimens were tested. The indirect tensile strength and failure strain were evaluated for both control and chemical modifiers mixtures. The samples were tested in a dry state at a temperature of $25^{\circ} \mathrm{C}$ with a loading rate of $50.8 \mathrm{~mm} /$ minute until the occurrence of the collapse with recording the failure load according to ASTM D6931 - 17 [20].

\section{Test Results}

\subsection{Marshall test results}

\subsubsection{Effect of type of additive on Marshall stability}

Figures (2,3 and 4) show the test results of Marshall stability of Addicrete PVS, Adibond 65, and Silica Gel respectively at different contents versus submerging time. The value of stability is decreased as the time of submerging increased for all tested molds as shown in the figures. This result may be because of wastewater which caused erosion 
of the sample due to breaking the bond between mixed components. It is found that the value of Marshall stability is approximately the same as dried original compared to the sample modified with $10 \%$ content of Addicrete PVS, 5\% of Adibond 65, and 10\% of Silica Gel after 15 days of submerging. These results may come up because using the different additives increased the stiffness of the mix to resist the erosion thus the mix was able to resist the external loads.

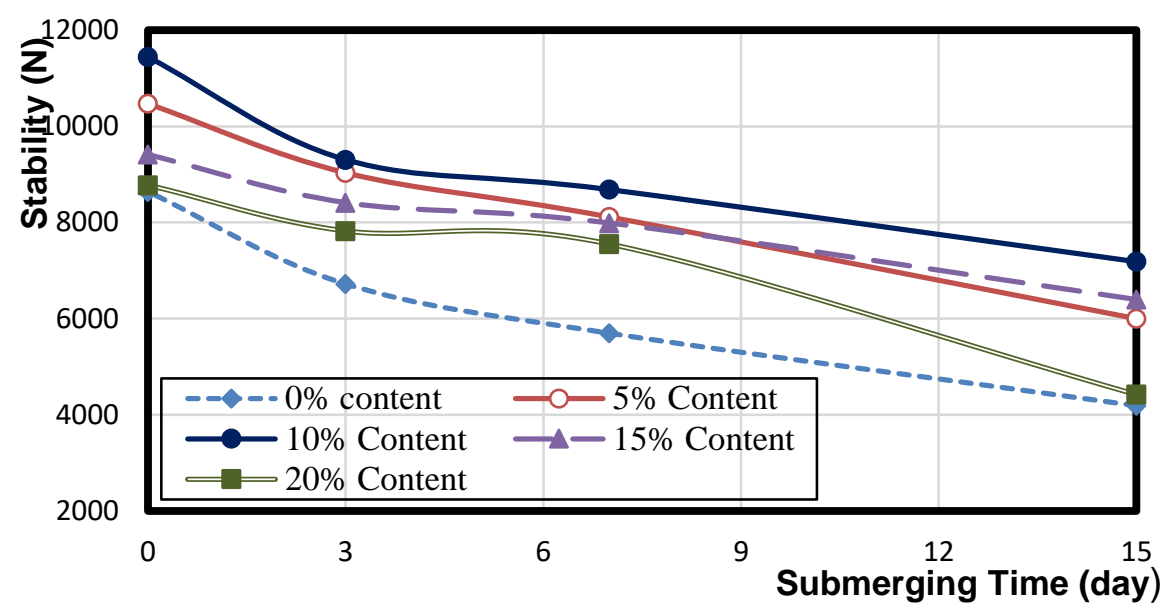

Fig.2. Effect of submerging time on Marshall stability for Addicrete PVS

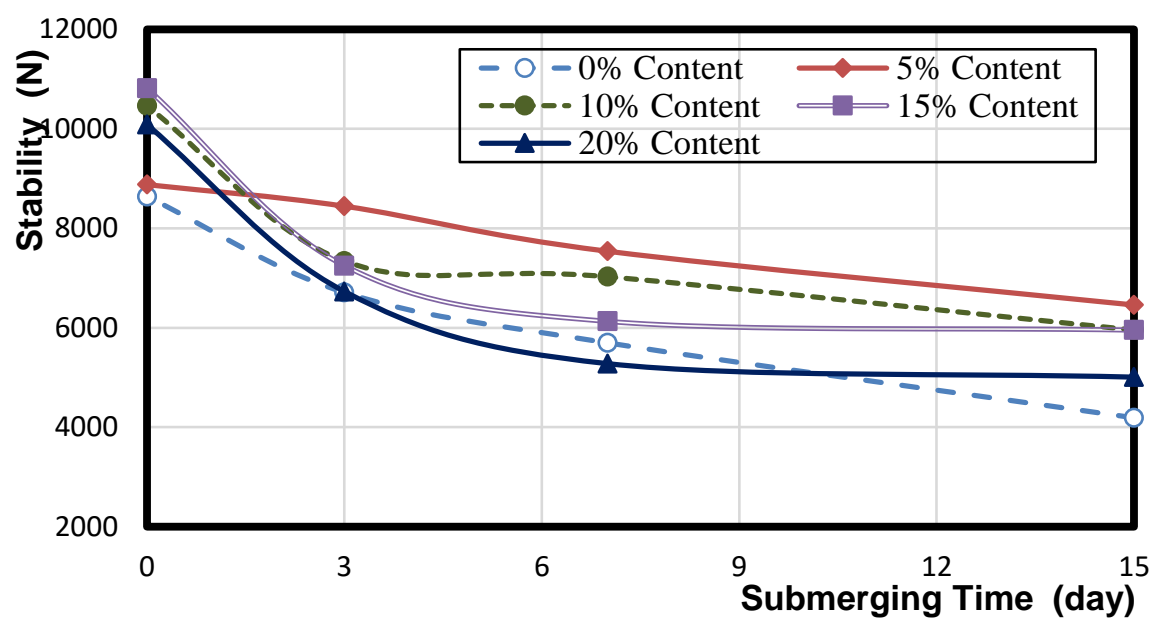

Fig.3. Effect of submerging time on Marshall stability for Adibond 65 


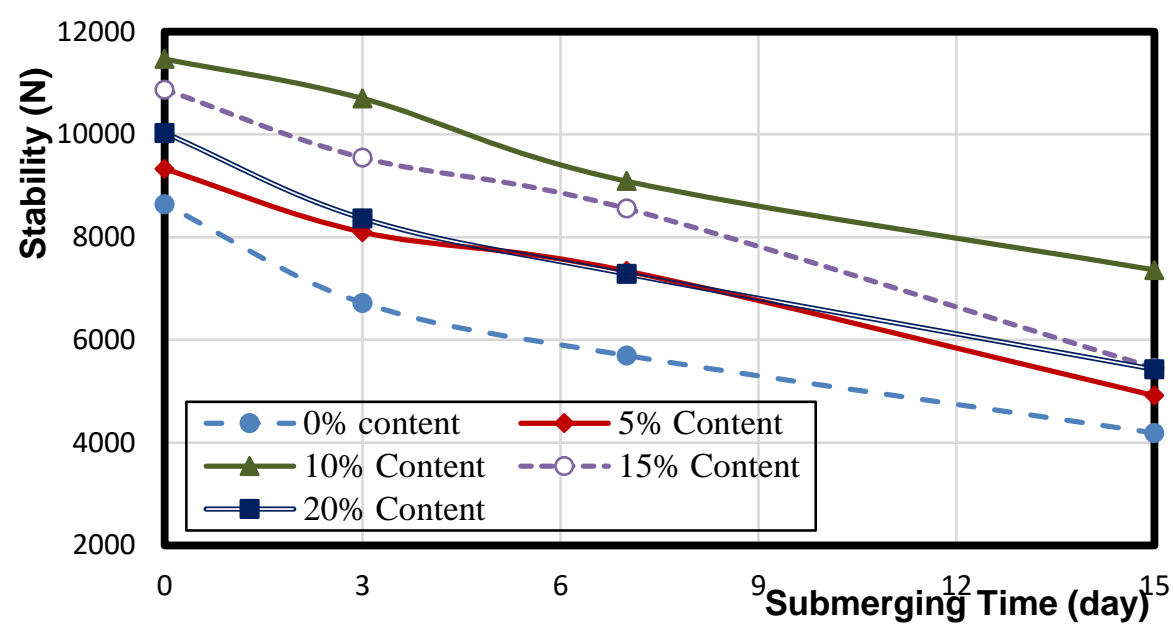

Fig.4. Effect of submerging time on Marshall stability for Silica Gel at different contents.

\subsubsection{Effect of type of additive on Marshall flow}

The relation between Marshall flow for modified mixtures with Addicrete PVS, Adibond 65, and Silica Gel at different contents and submerging time were shown in Figures $(5,6$, and 7) respectively. The value of flow is increased as the time of submerging increased for all tested molds as shown in the figures. The value of Marshall flow for modified mixtures was higher than the control mixture because adding different additives increase the value of Marshall stability. Also, the control mixtures had the lowest value of flow for all tested molds due to their low stability value as shown in the figures above.

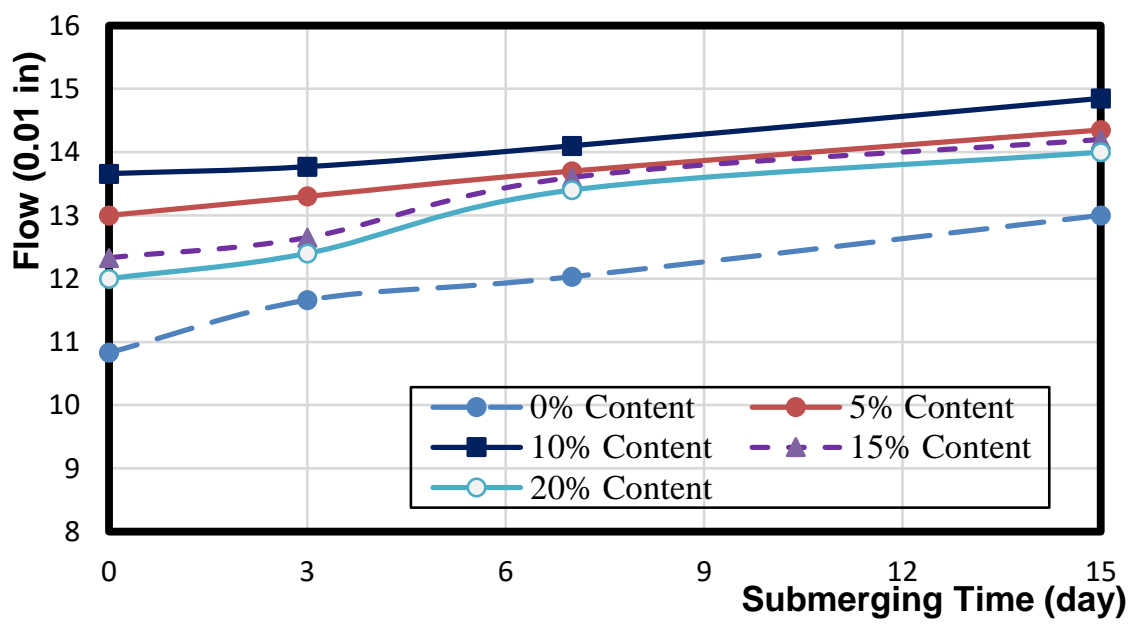

Fig.5. Effect of submerging time on flow for Addicrete PVS 


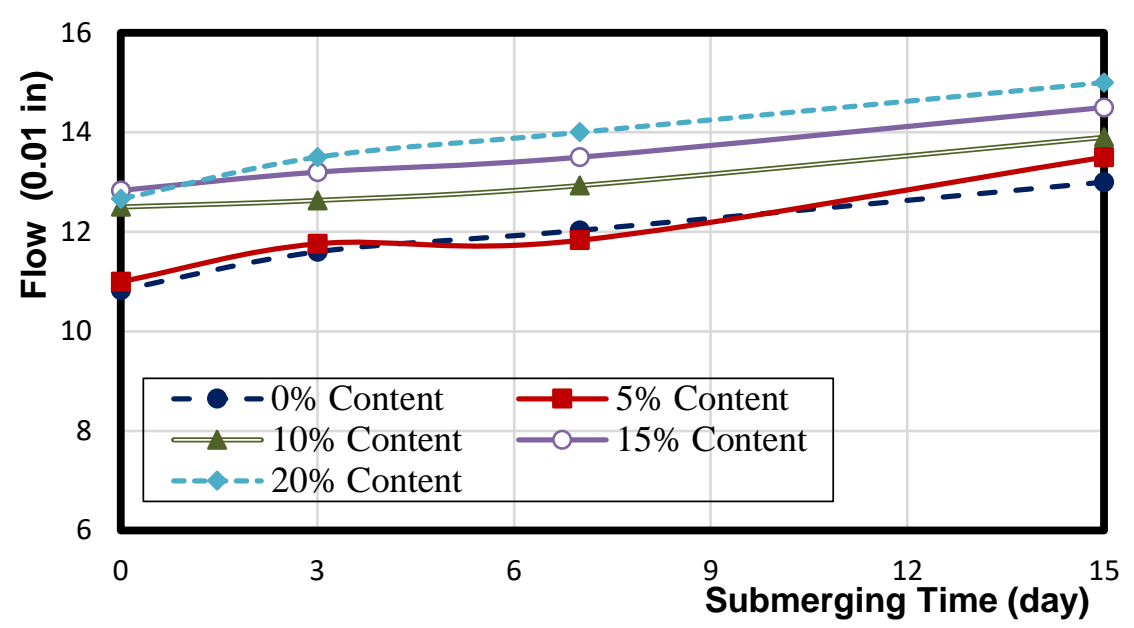

Fig.6. Effect of submerging time on flow for Adibond 65 .

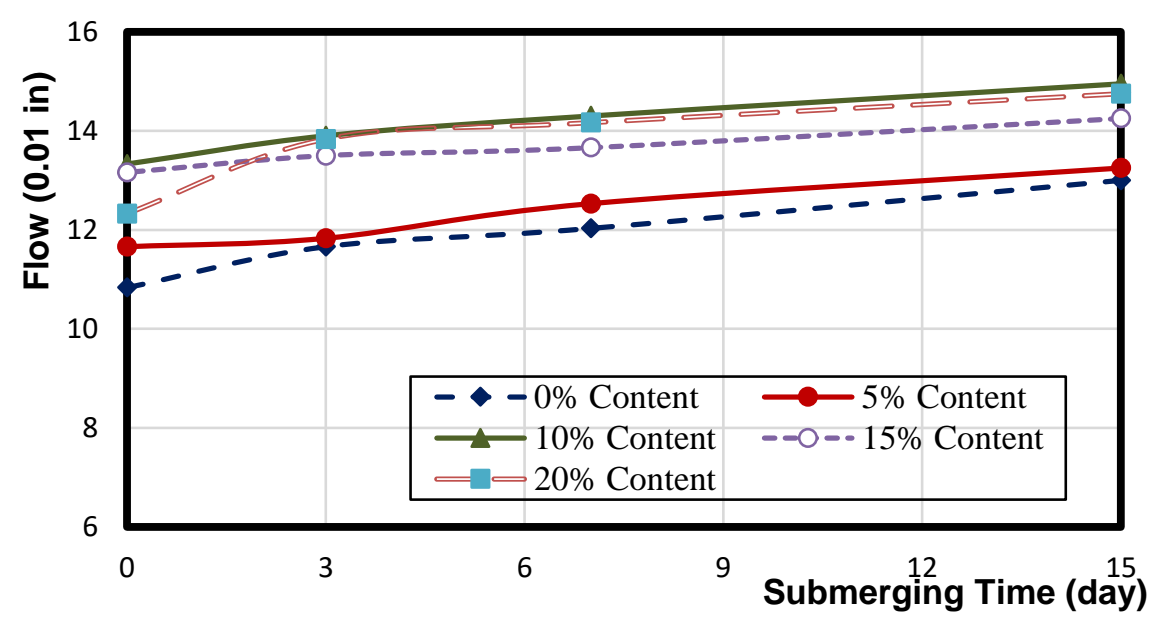

Fig.7. Effect of submerging time on flow for Silica Gel.

\subsubsection{Effect of type of additive on bulk density}

Figures $(8,9$, and 10) show the test results of bulk density for Addicrete PVS, Adibond 64, and Silica Gel respectively at different contents versus submerging time. The value of bulk density is increased as the time of submerging increased for all tested molds as shown in the figures. It reveals that the control mixtures had the highest value of bulk density than mixtures modified with Addicrete PVS and Silica Gel. This result may come up because the wastewater filled almost the voids between the mixture component which increased the weight of the sample consequently increased the density. Using Addicrete PVS and Adibond 65 decreased the value of bulk density than the control mix. These results 
may be due to using the additives prevented some of the water to permeate through the voids between the mixture component thus the weight of the sample was less than the unmodified sample. While modified mixtures with Silica Gel at $10 \%$ content had the highest bulk density in comparison to the original one as shown in Figure 10.

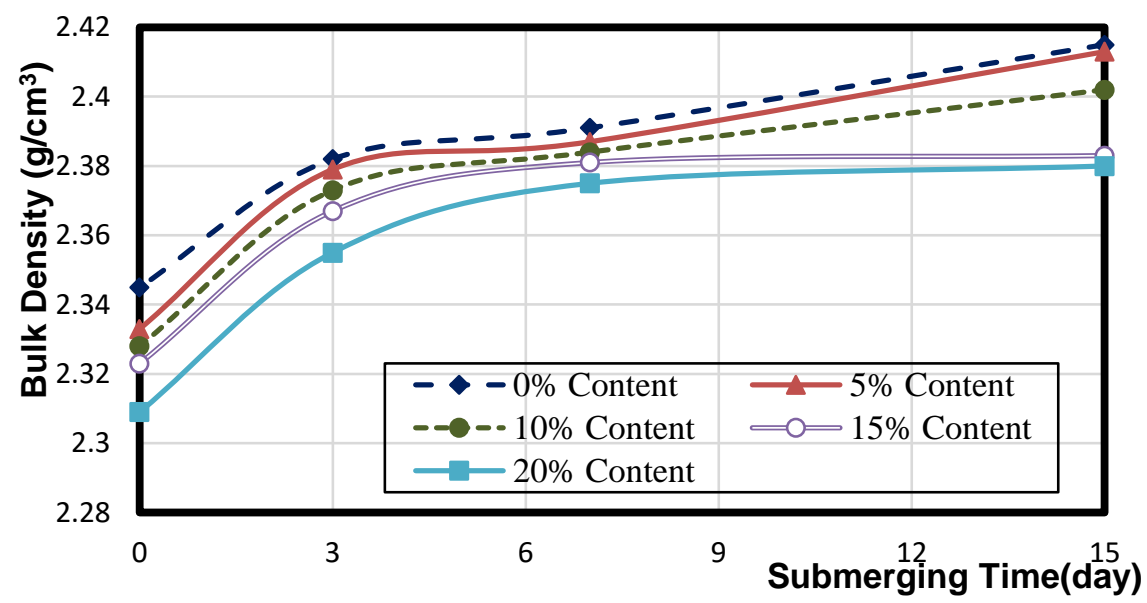

Fig.8. Effect of submerging time on bulk density for Addicrete PVS.

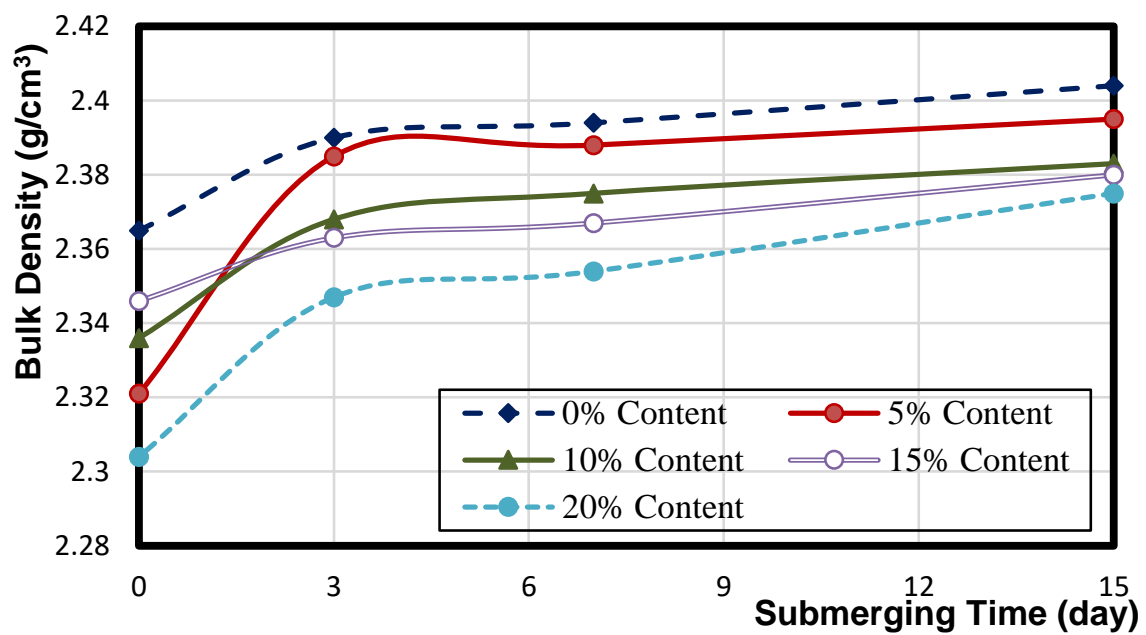

Fig.9. Effect of submerging time on bulk density for Adibond 65 . 


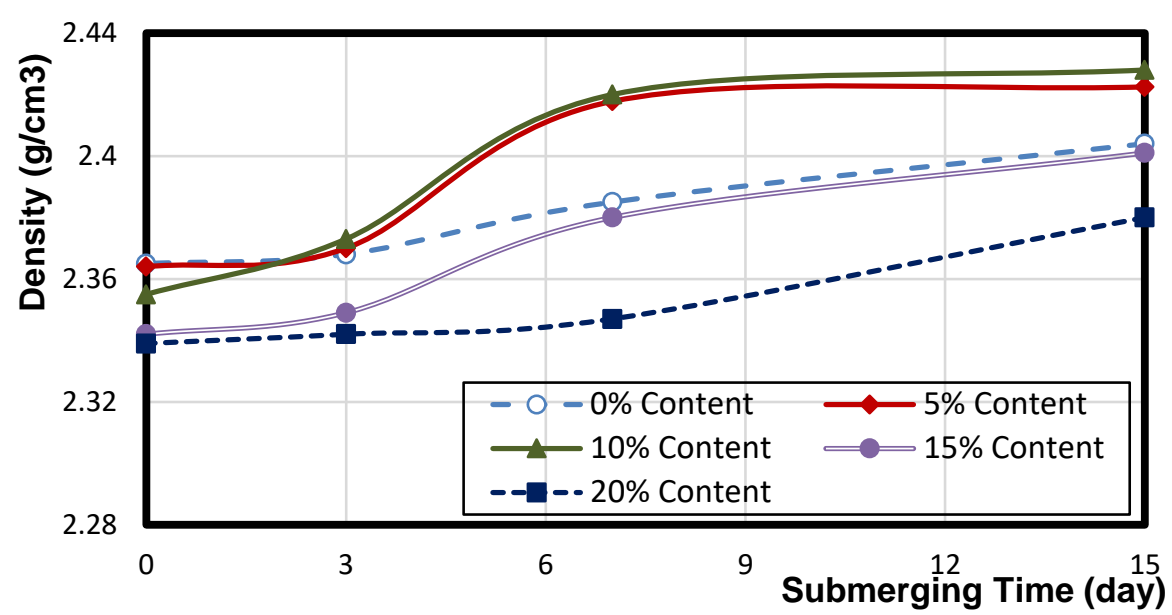

Fig.10. Effect of submerging time on bulk density for Silica Gel

\subsubsection{Effect of type of additive on Marshall quotient}

Figures $(11,12$, and 13) show the relation between Marshall quotient for modified mixtures with Addicrete PVS, Adibond 65, and Silica Gel respectively at different contents versus submerging time. The value of Marshall quotient is decreased with the increase of submerging time for all tested molds as shown in the figures. This result may be due to the decreasing of Marshall stability value with the increase of submerging time. It is found that the value of the Marshall quotient is approximately equal to $60 \%, 59.9 \%$, and $61.6 \%$ of the dried original compared to the sample modified with $10 \%$ content of Addicrete PVS, $5 \%$ of Adibond 65 , and $10 \%$ of Silica Gel respectively after 15 days of submerging in wastewater. These results may come up because using the different additives increased the value of stability as shown in Figures (2,3 and 4).

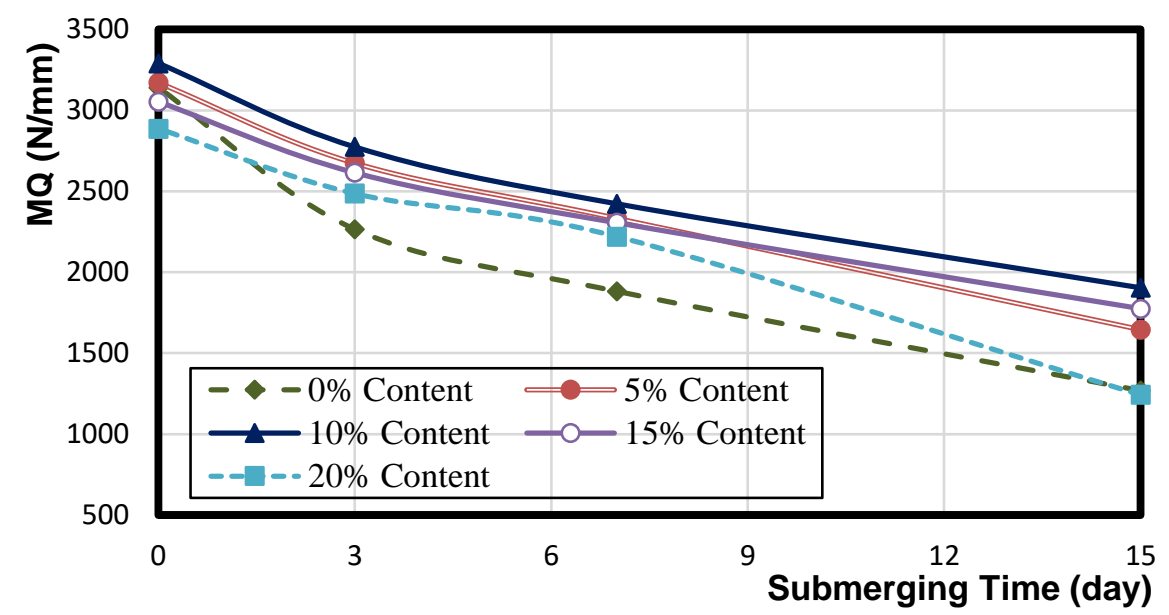

Fig.11. Effect of submerging time on Marshall quotient for Addicrete PVS 
Samir Azmy et al., Effect of Chemical Additive on the Performance of Asphalt Pavement...

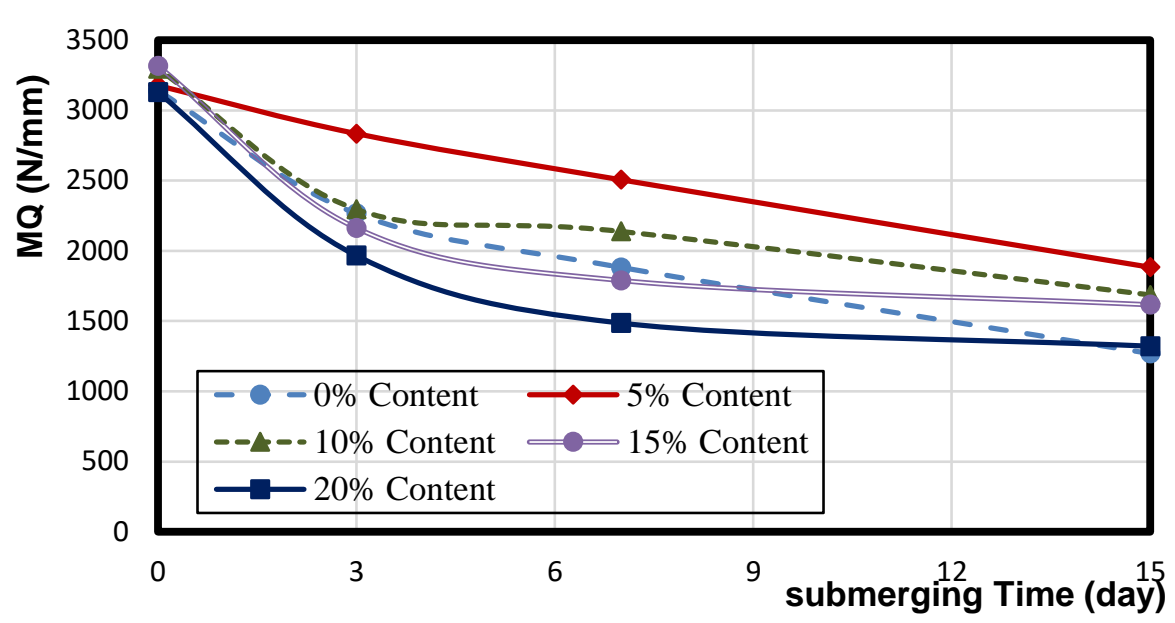

Fig.12. Effect of submerging time on Marshall quotient for Adibond 65

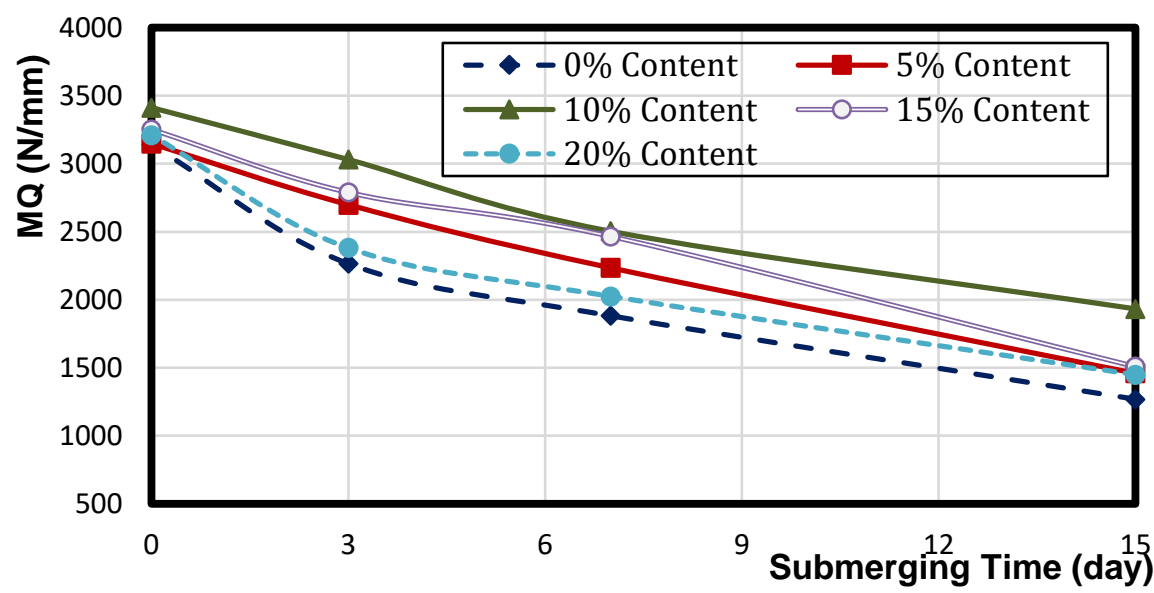

Fig.13. Effect of submerging time on Marshall quotient for Silica Gel

\subsubsection{Effect of type of additive on Marshall stiffness}

The relation between Marshall Stiffness of Addicrete PVS, Adibond 65, and Silica Gel respectively with different contents and submerging time was illustrated in Figures (14, 15, and 16). The value of Marshall stiffness is decreased with increasing time of submerging for all tested molds as shown in the figures. This result may be due to the decreasing of Marshall stability value with an increase of submerging time. It is found that the value of Marshall stability is approximately equal to $60.6 \%, 60.4 \%$, and $61.6 \%$ of the dried original compared to the sample modified with $10 \%$ content of Addicrete PVS, $5 \%$ of Adibond 65, and $10 \%$ of Silica Gel respectively after 15 days of submerging in 
wastewater. These results may come up because using the different additives increased the value of stability as shown in Figures (2,3 and 4).

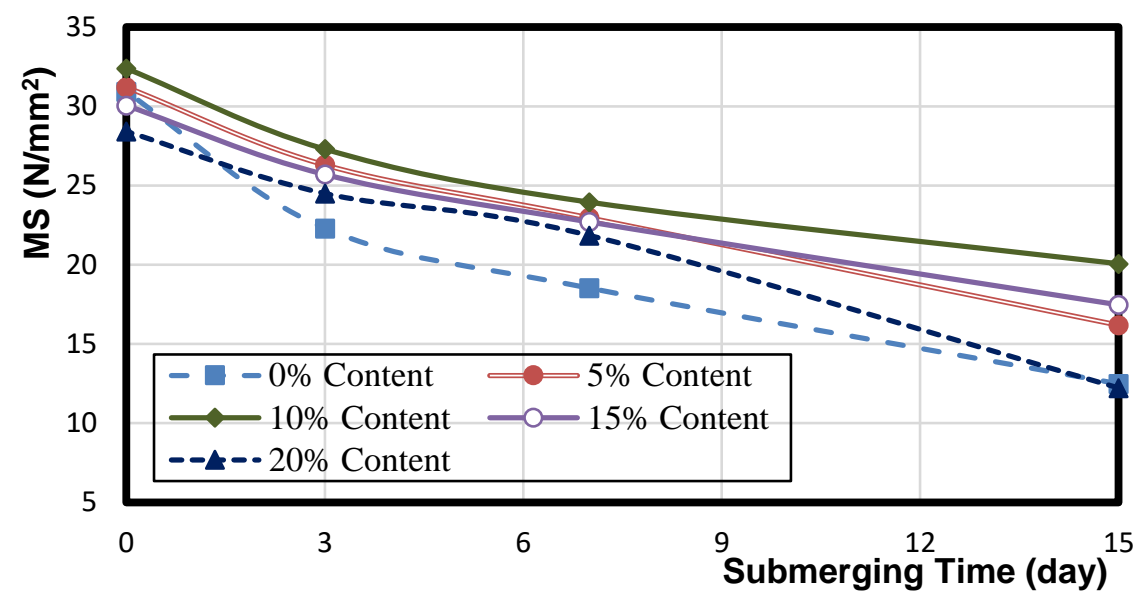

Fig.14. Effect of submerging time on Marshall stiffness for Addicrete PVS

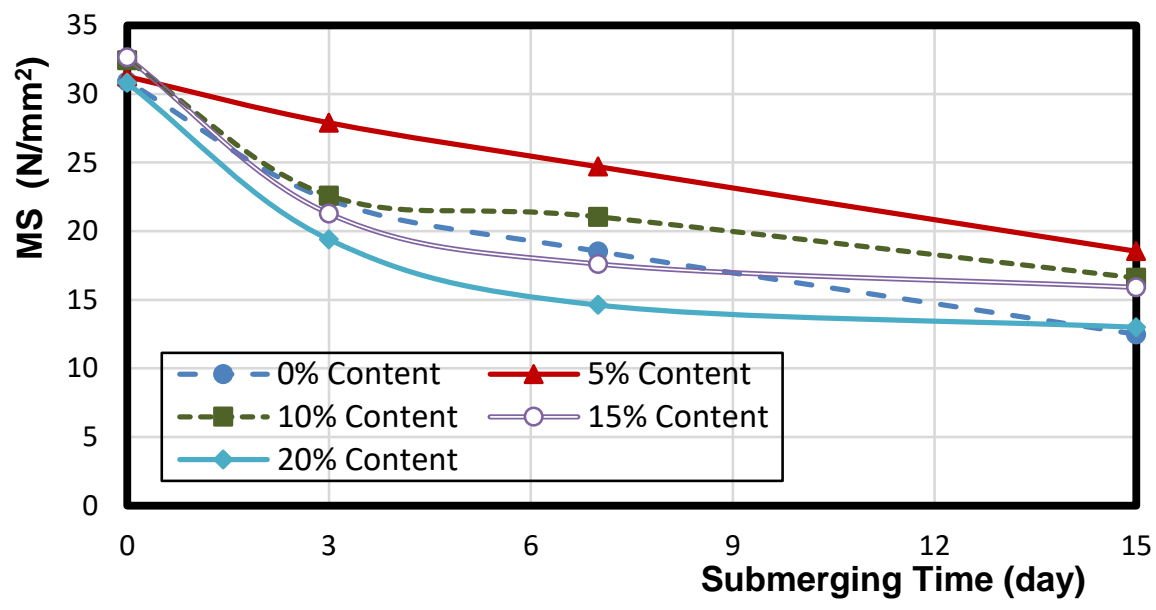

Fig.15. Effect of submerging time on Marshall stiffness for Adibond 65 


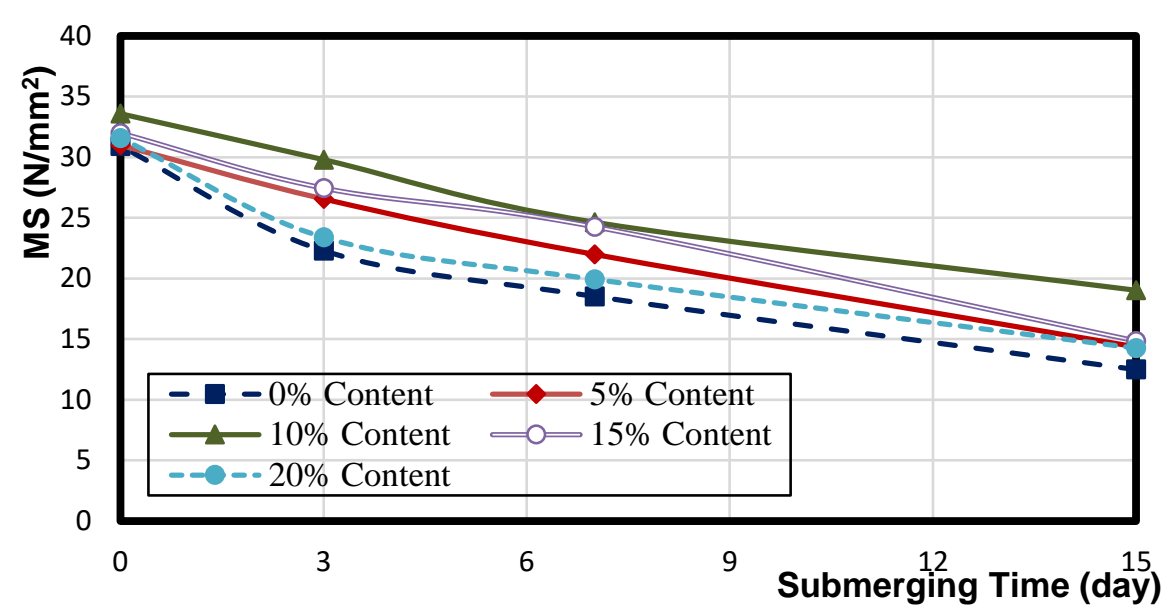

Fig.16. Effect of submerging time on Marshall stiffness for Silica Gel

\subsection{Indirect tensile test results}

\subsubsection{Effect of type of additive on indirect tensile strength}

The relation between indirect tensile strength (ITS)of modified mixtures with Addicrete PVS, Adibond 65, and Silica Gel at different contents versus submerging time were shown in Figures (17, 18, and 19) respectively. The value of ITS decreased with increasing time of submerging for all tested molds as shown in the figures. This result may be due to the decreasing of mixture ability to resist external loads due to the wastewater effect as shown from is low Marshall stability. It was found that the value of ITS is approximately equal to $95 \%, 94 \%$, and $80 \%$ of the dried original compared to the sample modified with $10 \%$ content of Addicrete PVS, 5\% of Adibond 65, and 10\% of Silica Gel respectively after 15 days of submerging.

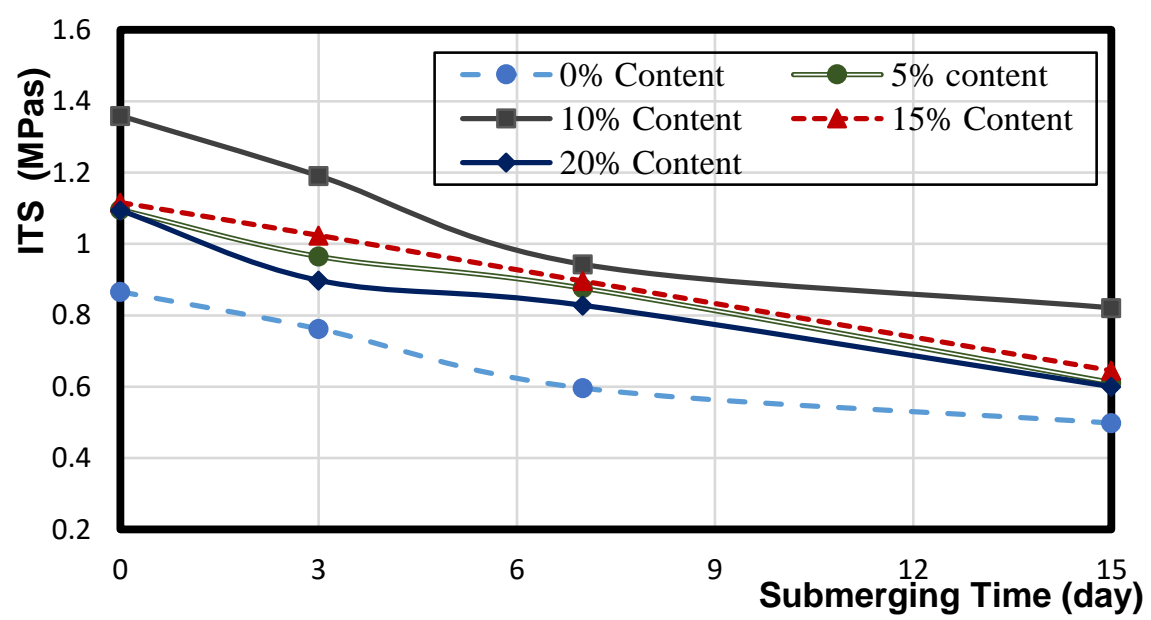

Fig.17. Effect of submerging time on ITS for Addicrete PVS. 


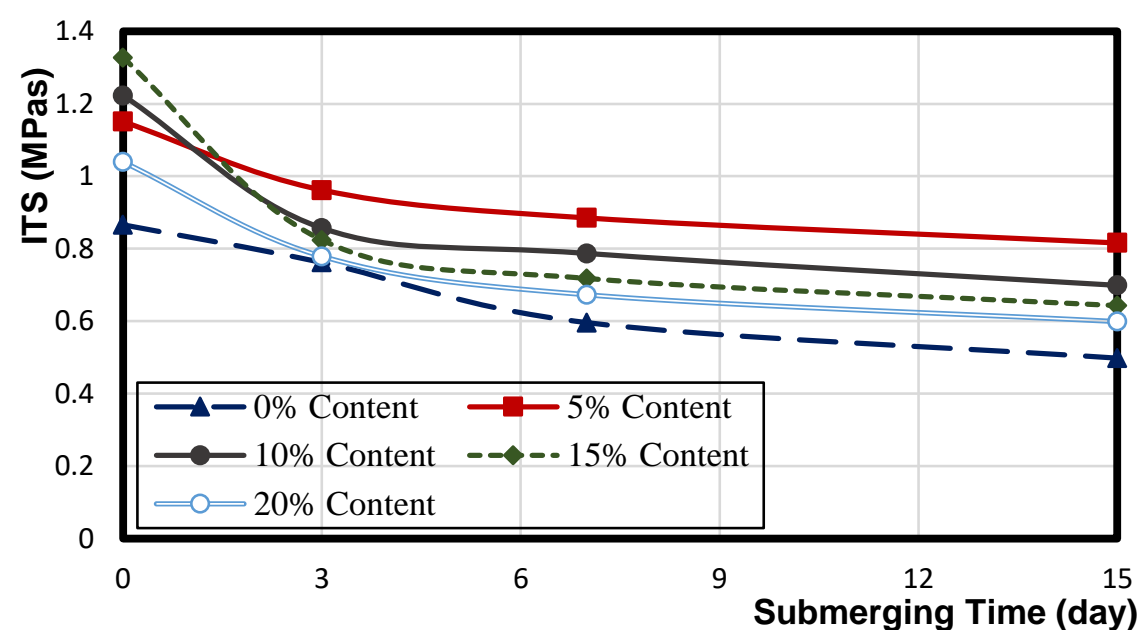

Fig.18. Effect of submerging time on ITS for Adibond 65

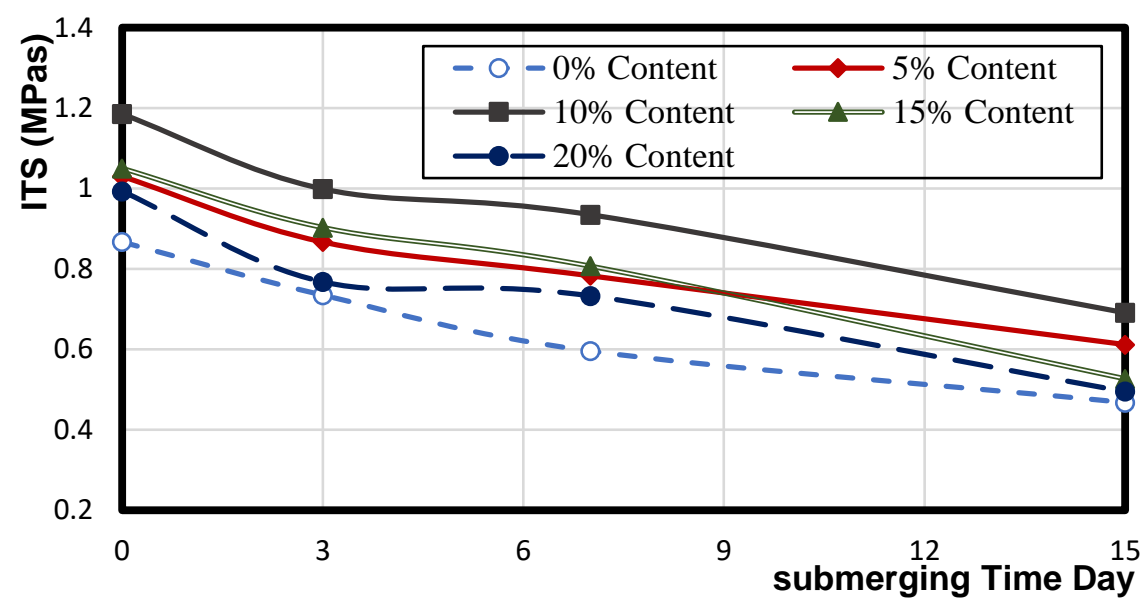

Fig.19. Effect of submerging time on ITS of Silica Gel.

\subsubsection{Effect of type of additive on failure strain}

The test results for failure strain for modified mixtures with Addicrete PVS, Adibond 65, and Silica Gel with different contents and immersing time were shown in Figures (20,21, and 22) respectively. The value of failure strain is increased as the time of immersing in wastewater increased for all tested molds as shown in the figures. The value of failure strain for modified mixtures was higher than the control mixture because adding different additives increase the value of indirect tensile strength (ITS) consequently increases the value of strain. 
Samir Azmy et al., Effect of Chemical Additive on the Performance of Asphalt Pavement...

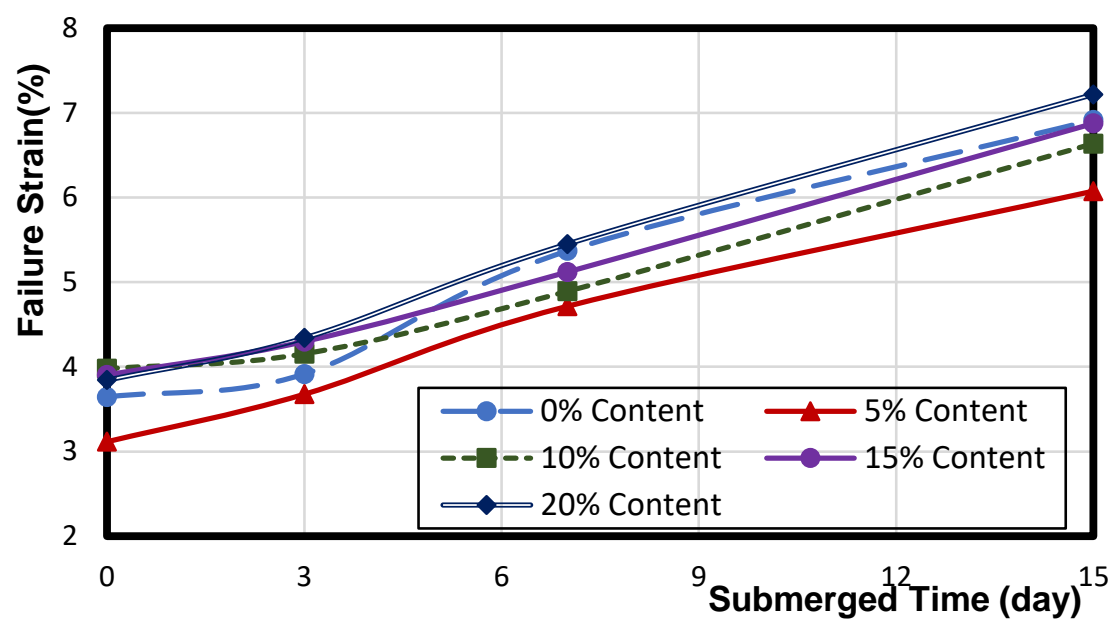

Fig.20. Effect of submerging time on failure strain for Addicrete PVS

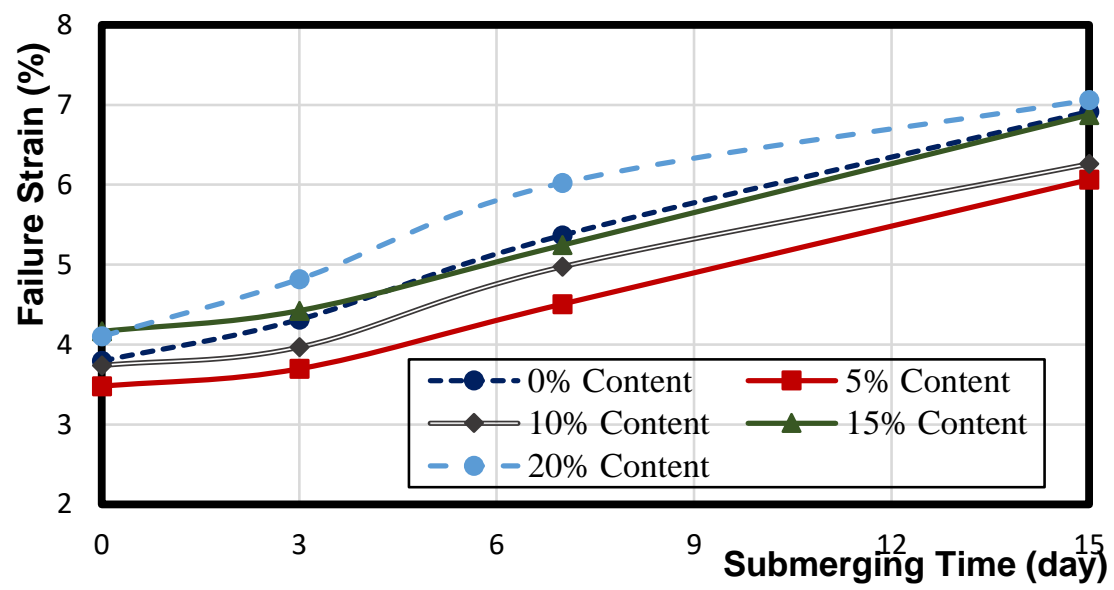

Fig.21. Effect of submerging time on failure strain for Adibond 65

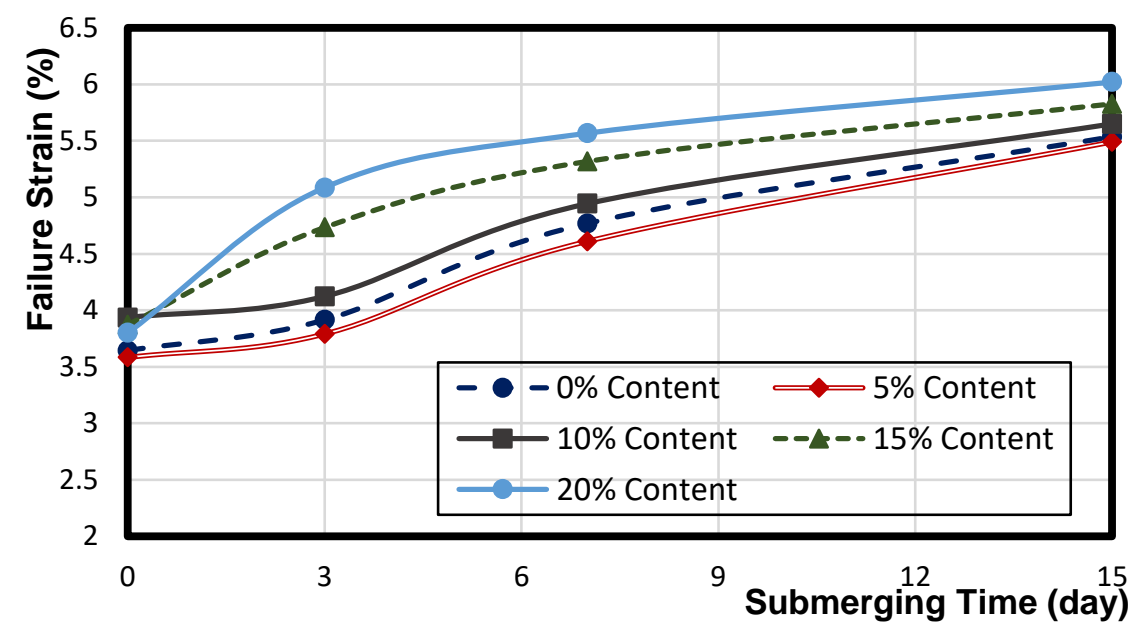

Fig.22. Effect of submerging time on failure strain for Silica Gel. 


\subsection{Comparison between types of additives}

\subsubsection{Marshall stability}

The relation between Marshall stability and submerging time for different types of additives were illustrated in Figure 23. The results showed that the stability increased with using different types of additives comparing with the original mix. Using Addicrete PVS and Silica gel at $10 \%$ content increased the value of stability by $71.5 \%$ and $68.5 \%$ respectively. Also, using Adibond 65 at $5 \%$ increased the value by $54.1 \%$ It is clear from the results that using Addicrete PVS had the highest value of increasing in the stability.

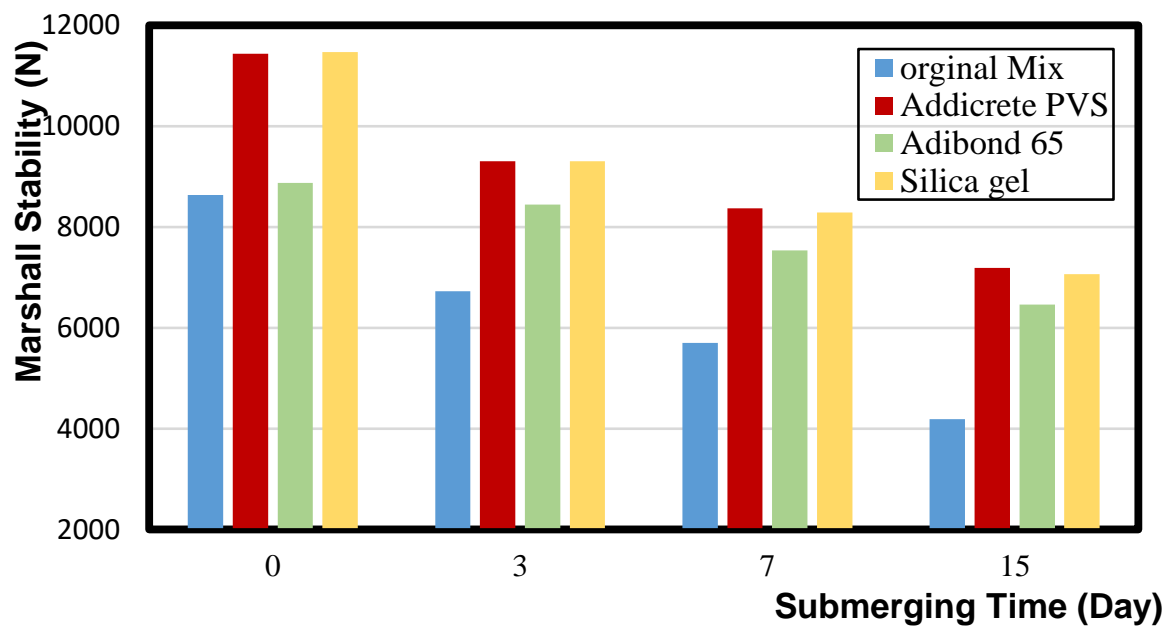

Fig.23. Marshall stability versus submerging time for different additives

\subsubsection{Indirect tensile strength}

Figure 24 illustrates the relationship between indirect tensile strength (ITS) and submerging time for different types of additives. The results showed that the stability increased with using different types of additives comparing with the original mix. Using Addicrete PVS and Silica gel at $10 \%$ content increased the value of ITS by $65 \%$ and $48.2 \%$ respectively. Also, using Adibond 65 at $5 \%$ increased the value by $60.6 \%$ It is clear from the results that using Addicrete PVS had the highest value of increasing in ITS. 


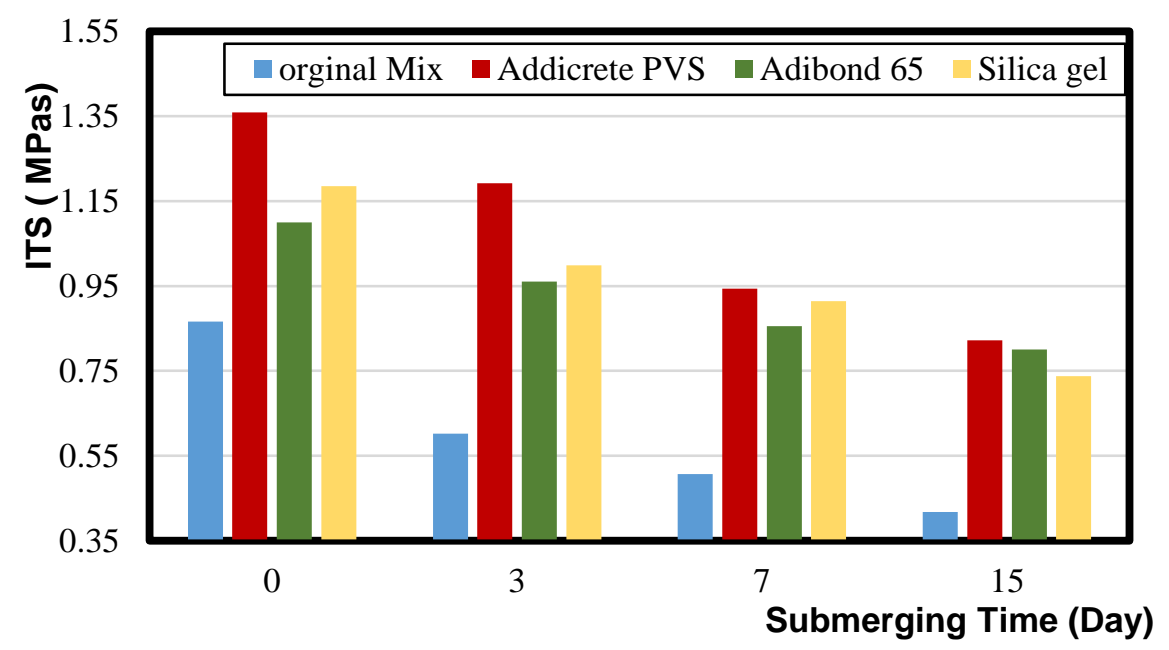

Fig.24. Indirect tensile strength (ITS) versus submerging time for different additives

\subsubsection{Tensile strength ratio}

the relationship between tensile strength ratio (TSR) and submerging time for different types of additives was shown in Figure 25. The results showed that the value of TSR deceased with increasing the submerging time in wastewater. Also, results revealed that using the different additives decreased the effect of wastewater on reduction the value of TSR comparing to the original mix.

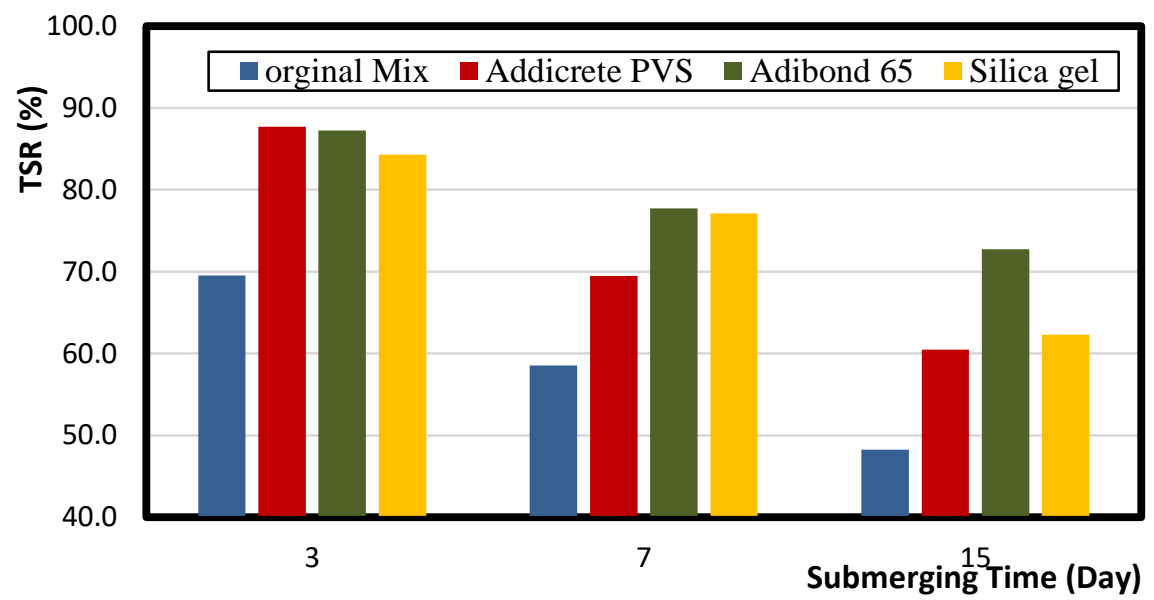

Fig.25. Tensile strength ratio (TSR) versus submerging time for different additives 


\section{Relation Between Indirect Tensile Strength and Stability for Addicrete PVS.}

By using experimental results and the numerical analysis with Data fit Software an experimental model was performed for the prediction of the relation between Indirect tensile strength and Marshall stability for modified mixtures with Addicrete PVS at $10 \%$ content for a different submerging time as shown in Figure 26.

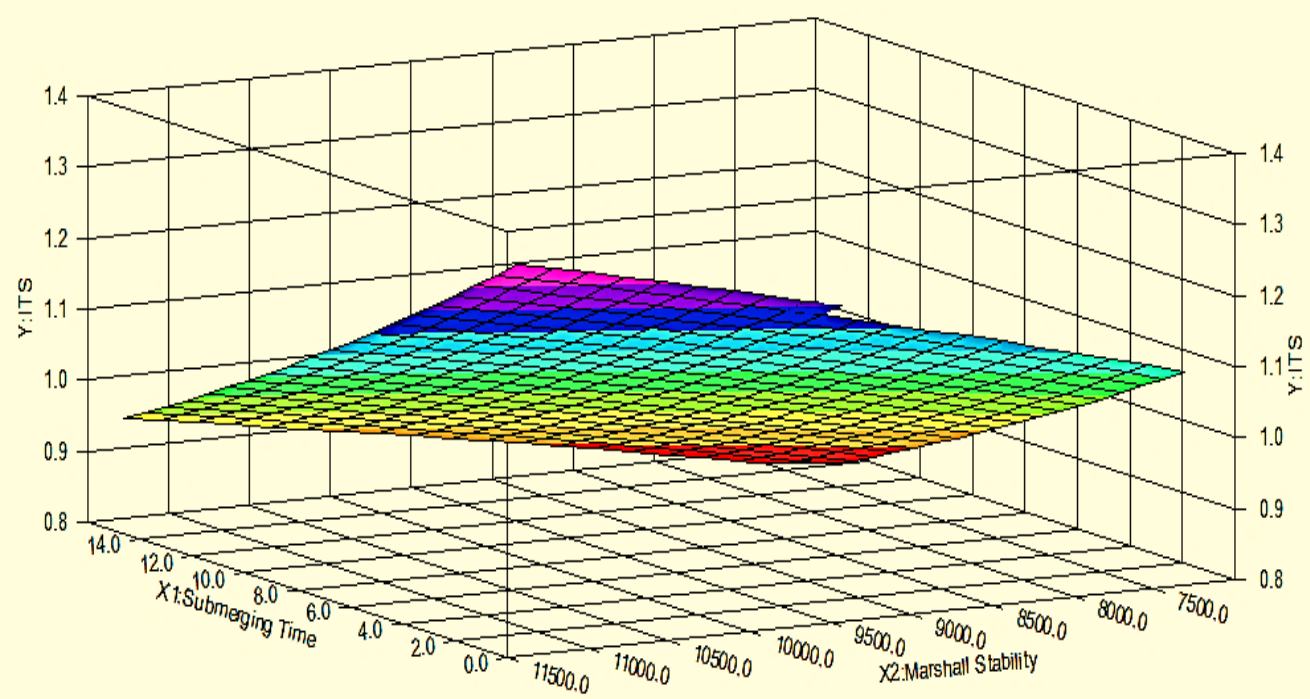

Fig.26. Model Plot

Mathematical model

$$
\mathrm{Y}=2.5 * 10^{-2} * 0.9972^{\mathrm{x}_{1}} * \mathrm{x}_{2}{ }^{0.427} \quad R^{2}=94.8 \%
$$

Where:

Y The Indirect Tensile Strength (ITS), MPas

$\mathrm{X}_{1} \quad$ Submerging Time in (days)

$\mathrm{X}_{2} \quad$ Marshall Stability (N)

\section{Conclusions}

It was noticed from the results that wastewater negatively affected the performance of all types of mixtures and this effect increased with the increase in the immersion time. 
- The results showed that the best content for adding these additives to the mixture was $10 \%$ for using Addicrete PVS and Silica gel while it was 5\% for using Adibond 65.

- Submerging the different mixtures in wastewater caused a loss in Marshall stability value. The value of the loss was $51.5 \%$ for the original sample awhile was $37.2 \%$ and $38.4 \%$ for Modified mixtures with Addicrte PVS and Silica gel at $10 \%$ content respectively. Also, the Marshall loss value was $27.3 \%$ whereas modified mixtures with Adibond 65 at $15 \%$ content.

- Utilizing Addicrete PVS and silica Gel at $10 \%$ content increased the stability value of the submerged mixture by $71.5 \%$ and $68.5 \%$ respectively while using Adibond 65 at 5\% content increased the stability value by $54.1 \%$ in comparison to the control mix after 15 days of submerging in wastewater.

- The value of Marshall flow and failure strain of all mixtures increased with increasing submerging time.

- The indirect tensile strength value after 15 days of submerging the different mixtures was decreased by $42.5 \%, 39.6 \%, 27.3 \%$, and $37.7 \%$ for original mix, modified mix with Addicrete PVS, Silica Gel at $10 \%$ content, and Adibond 65 at $5 \%$ content respectively.

- Utilizing Addicrete PVS and silica Gel at $10 \%$ content increased the indirect tensile strength value of the submerged mixture by $65 \%$ and 48.2\% respectively while using Adibond 65 at 5\% content increased the value by $60.6 \%$ in comparison to the control mix after 15 days of submerging in wastewater.

- The best material which reduced the wastewater effect to a minimum level was Addicrete PVS.

\section{References}

[1] Caro, S., E. Masad, A. Bhasin, and D. N. Little. "Moisture Susceptibility of Asphalt Mixtures", Part 1: Mechanisms. International Journal of Pavement Engineering. Vol. 9, No. 2(a), pp. 81-98,2008.

[2] Bhasin, A., D. N. Little, K. L. Vasconcelos, and E. Masad. "Surface Free Energy to Identify Moisture Sensitivity of Materials for Asphalt Mixes". In Transportation Research Record: Journal of the Transportation Research Board, No. 2001, Transportation Research Board of the National Academies, Washington, D.C., pp. 37-45,2007.

[3] Putman B. J, Amirkhanian S. N. "Utilization of Waste Fibers in Stone Matrix Asphalt Mixtures" [J]. Resources, Conservation and Recycling, 42: 265- 
274,2000 .

[4] Ghada S. Moussa, Ashraf Abdel-Raheem and Talaat Abdel-Wahed," Investigating the Moisture Susceptibility of Asphalt Mixtures Modified with High-Density Polyethylene “, Vol. 48, No. 5, PP. 765-782, 2020.

[5] F. Moghadas Nejad, A. Azarhoosh, and G. H. Hamedi, "Effect of high-density polyethylene on the fatigue and rutting performance of hot mix asphalt-a laboratory study," Road Mater. Pavement Des. vol. 15, no. 3, pp. 746-756, 2014.

[6] H. M. Rasel, M. N. Rahman and T. U. Ahmed, "Study of Effects of Waste PVC on the Properties of Bituminous Mixes", S-JPSET, ISSN: 2229-7111, Vol. 2, Issue 2,2011.

[7] Prasad. B, Varun. K, Ashok. A, Ganesh. R, "Performance Evaluation of Recycled Bitumen Before and After the Addition of Plastic Waste", International Journal of Engineering Research \& Technology (IJERT), Vol. 2 Issue 3, ISSN: 2278-0181, March 2013.

[8] Rahman, Md. Nobinur, et al., "Performance Evaluation of Waste Polyethylene and PVC on Hot Asphalt Mixtures. "American Journal of Civil Engineering and Architecture ,97-102, 2013.

[9] Goh SW, Akin M, You Z, Shi X, "Effect of deicing solutions on the tensile strength of micro or Nano modified asphalt mixture", Construction and Building Materials; 25:195-200, 2011.

[10] Aksoy A, Samlioglu K, Tayfur S, Ozen H., "Effects of Various Additives on the Moisture Damage Sensitivity of Asphalt Mixtures"., Journal of Construction Building Materials; 19: 11-18, 2005.

[11] Ataelmanan M, Feng CP, Al-Hadidy AI. "Laboratory Evaluation of HMA with High Density Polyethylene as a Modifier". Journal of Construction Building Materials;25: 2764-2770, 2011.

[12] Mahabir Panda; Mayajit Mazumdar "Utilization of Reclaimed Polyethylene in Bituminous Paving Mixes" Journal of Materials in Civil Engineering, ASCE 14 (6), pp. 527-530,2002.

[13] Hugo F.; Nachenius R. "Some -Rubber Asphalt and Binders", Proceeding of the Association of Asphalt Paving Technologists, vol.58, pp. 303-336, (1989).

[14] C. ASTM, “128-15. “," Stand. Test Method Relat. Density (Specific Gravity) Absorpt. Fine Aggregate", ASTM Curr. Ed. Approv. Jan, vol. 1, 2015.

[15] International, "ASTM C128-15 Standard Test Method for Relative Density (Specific Gravity) and Absorption of Fine Aggregate." ASTM International West Conshohocken (PA), 2015.

[16] ASTM, "D854.," Stand. test methods Specif. gravity soil solids by water Pycnom",2014.

[17] A. ASTM, "C131-06 Standard Test Method for Resistance to Degradation of Small-Size Coarse Aggregate by Abrasion and Impact in the Los Angeles Machine." Conshohoken, PA: ASTM, 2006.

[18] CMB, Engineer Guide ,2002.

[19] http://wikipedia.org/w/index. 
Samir Azmy et al., Effect of Chemical Additive on the Performance of Asphalt Pavement...

[20] ASTM D6931-17, Standard Test Method for Indirect Tensile (IDT) Strength of Asphalt Mixtures, ASTM International, West Conshohocken, PA, 2017. 


\section{تاثير استخدام الاضافات الكيميائية على اداء الرصف الاسفلتى

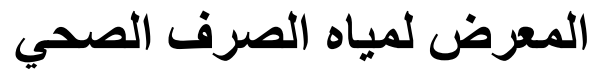

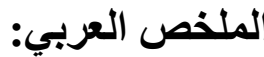

من المعروف ان المياه هى العدو الاول للرصف الاسفلتى وتزداد خطورته عندما تكون

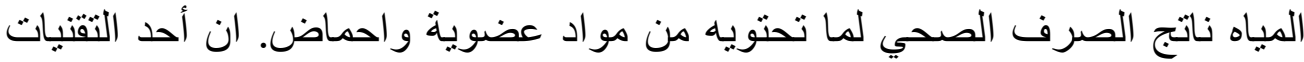

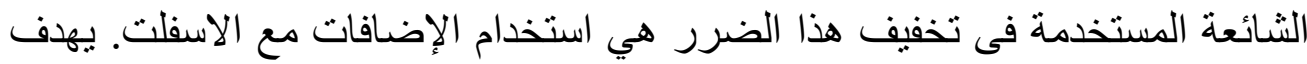

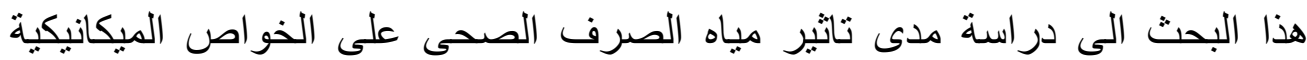

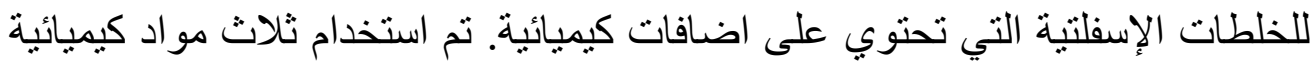

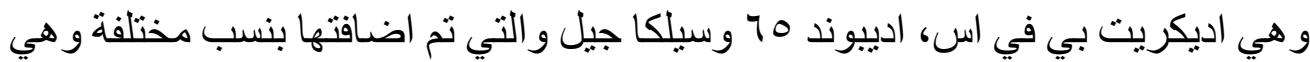

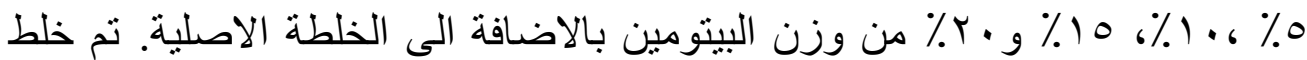

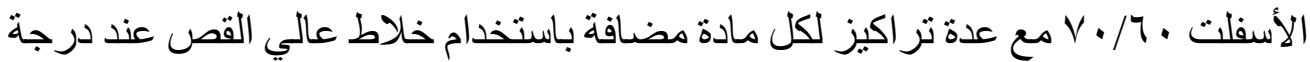

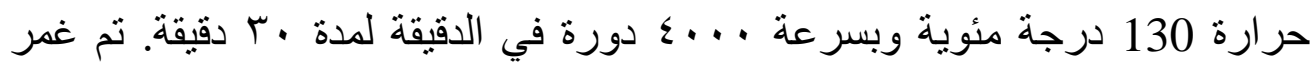

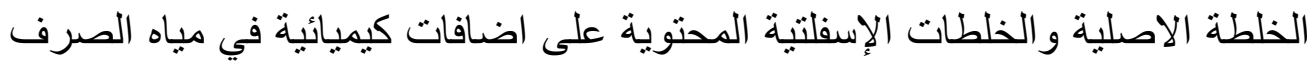

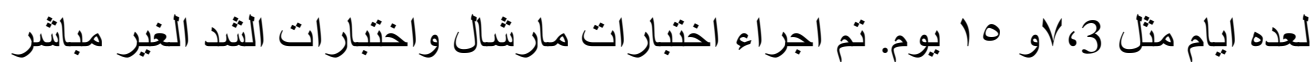

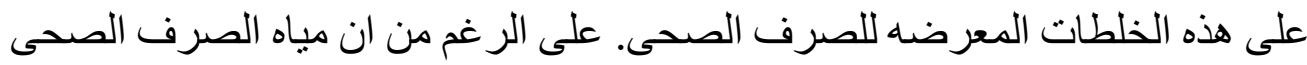

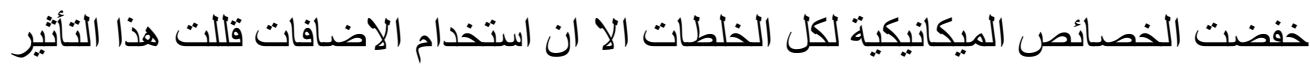

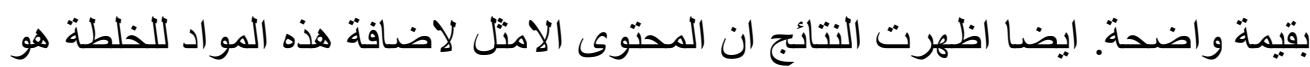

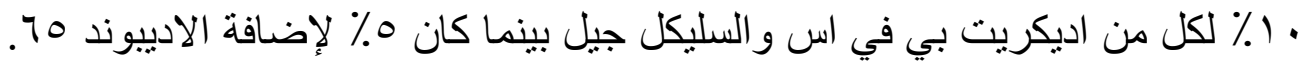

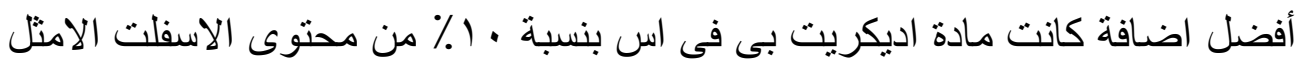

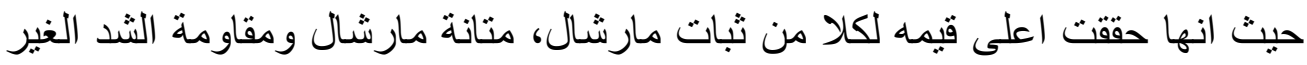
مبانر. 